Article

\title{
Corrosion and Tensile Behaviors of Ti-4Al-2V-1Mo-1Fe and Ti-6Al-4V Titanium Alloys
}

\author{
Yanxin Qiao ${ }^{1} \oplus$, Daokui $\mathrm{Xu}^{2, *}$, Shuo Wang ${ }^{1,2,3}$, Yingjie Ma ${ }^{2, *}$, Jian Chen ${ }^{1}$, Yuxin Wang ${ }^{1} \mathbb{D}$ and \\ Huiling Zhou ${ }^{1}$ \\ 1 School of Materials Science and Engineering, Jiangsu University of Science and Technology, Zhenjiang \\ 212003, China; yxqiao@just.edu.cn (Y.Q.); 1910221@mail.neu.edu.cn (S.W.); jchen496@uwo.ca (J.C.); \\ ywan943@163.com (Y.W.); zhouhl@just.edu.cn (H.Z.) \\ 2 Institute of Metal Research, Chinese Academy of Sciences, Shenyang 110016, China \\ 3 School of Materials Science and Engineering, Northeastern University, Shenyang 110004, China \\ * $\quad$ Correspondence: dkxu@imr.ac.cn (D.X.); yjma@imr.ac.cn (Y.M.); Tel.: +86-24-2392-8381 (D.X.)
}

Received: 12 October 2019; Accepted: 6 November 2019; Published: 11 November 2019

\begin{abstract}
X-ray diffraction (XRD), scanning electron microscope (SEM), immersion, electrochemical, and tensile tests were employed to analyze the phase constitution, microstructure, corrosion behaviors, and tensile properties of a Ti-6Al-4V alloy and a newly-developed low cost titanium alloy Ti-4Al-2V-1Mo-1Fe. The results showed that both the Ti-6Al-4V and Ti-4Al-2V-1Mo-1Fe alloys were composed of $\alpha$ and $\beta$ phases. The volume fractions of $\beta$ phase for these two alloys were $7.4 \%$ and $47.3 \%$, respectively. The mass losses after 180-day immersion tests in $3.5 \mathrm{wt} . \% \mathrm{NaCl}$ solution of these alloys were negligible. The corrosion resistance of the Ti-4Al-2V-1Mo-1Fe alloy was higher than that of the Ti-6Al-4V alloy. The tensile tests showed that the Ti-4Al-2V-1Mo-1Fe alloy presented a slightly higher strength but a lower ductility compared to the Ti-6Al-4V alloy.
\end{abstract}

Keywords: titanium alloy; corrosion; passive film; mechanical behavior

\section{Introduction}

Titanium and its alloys are widely used in aerospace [1,2], marine [3], chemical [4,5], and biomedical [6-8] fields due to their excellent mechanical properties, high corrosion resistance, and good biocompatibility. Their high corrosion resistance in aggressive environments is ensured by the formation of a compact and chemically-stable oxide film, mainly composed of titanium oxide, $\mathrm{TiO}_{2}$, which spontaneously covers the metal surface to protect the metal substrate [9-11]. The corrosion behaviors of the commercial Ti-6Al-4V alloy vary with corrosive environments. Yue et al. [12] found that the Ti-6Al-4V alloy exhibited a poor corrosion behavior in a solution with a high $\mathrm{Cl}^{-}$concentration or in acid environments with a local accumulation of $\mathrm{Cl}^{-}$ions. Blanco-Pinzon et al. [13] reported that the Ti-6Al-4V alloy was susceptible to corrosion in $\mathrm{H}_{2} \mathrm{SO}_{4}$ solution but its corrosion resistance could be significantly improved by alloying $\mathrm{Pd}$ and Ni. Wang et al. [5] investigated the effects of alloying elements $\mathrm{Pd}, \mathrm{Mo}$, and $\mathrm{Ni}$ on the corrosion behavior of titanium alloy in $\mathrm{H}_{2} \mathrm{SO}_{4}$ solution containing fluoride ions, and found that these alloying elements had no influence on the interaction of the $\mathrm{F}^{-}$ ions with titanium matrix, and on the film composition. The addition of $\mathrm{Ni}$ accelerated the cathodic reactions while the addition of Mo retarded the anodic process [5]. Newman et al. [14,15] found that Mo located at defect sites preferentially dissolved, leading to the formation of stable Mo oxides to decrease the anodic dissolution rate [16].

Generally, element alloying is an effective method to improve the mechanical properties of titanium and its alloys $[17,18]$. Since Fe and Al elements are characteristic of low toxicity and cost [19-21], they are added into the titanium and titanium alloys, and the effect of $\mathrm{Fe}$ or $\mathrm{Al}$ alloying on the 
mechanical and corrosion properties of titanium alloys has been studied. It is reported that the Ti-4.5Al-3V-2Mo-2Fe alloy has superior mechanical properties to the Ti-6Al-4V alloy [17] due to its microstructural characteristics and element alloying (i.e., Mo and Fe). Lu et al. [22] investigated the mechanical properties and electrochemical corrosion behaviors of Ti-6Al, Ti-6Al-4V, and Ti-6Al-xFe alloys, and found that the Ti-6Al-4Fe alloy possessed the lowest Young's modulus and exhibits the highest strength:modulus ratios, and the Ti-6Al-xFe alloys exhibited a higher corrosion resistance in simulated human body fluid (SBF) than both the Ti-6Al and Ti-6Al-4V alloys. However, the corrosion resistance of the Ti-6Al-xFe alloys decreased with the increasing Fe content, suggesting that the content of Fe added into the titanium alloys needed to be controlled at a lower level to achieve a better corrosion performance. It is consistent with the results conducted by Pimenova et al. [21] and Hsu et al. [23,24]. When the concentration of $\mathrm{Al}$ was higher than $15 \mathrm{wt} . \%$, Ti-xAl-yFe alloys underwent severe pitting corrosion due to the precipitates of $\beta$ phase and uneven distribution of the alloying elements [21]. Thus, more work has to be performed to clarify the effect of $\mathrm{Al}$ and Fe alloying on the corrosion and mechanical performances of titanium alloys, especially when Mo is added to improve the resistance of localized corrosion.

In this research, the Ti-4Al-2V-1Mo-1Fe alloy developed by the Institute of Metal Research, Chinese Academy of Sciences (IMR), was investigated. This type of alloy has lower contents of $\mathrm{Al}$ and $\mathrm{V}$ but higher contents of $\mathrm{Mn}$ and Fe. The cost of this alloy is relatively low, providing a potential alternative to the Ti-6Al-4V alloy. The aim of this work is to investigate the corrosion behavior of this newly-developed alloy in a simulated marine environment ( $3.5 \mathrm{wt} . \% \mathrm{NaCl}$ solution), and its tensile property. The difference of alloy property between Ti-6Al-4V and Ti-4Al-2V-1Mo-1Fe alloys was systematically studied.

\section{Experimental Details}

The materials used in the present study were the commercial Ti-6Al-4V alloy, and the Ti-4Al-2V-1Mo-1Fe alloy fabricated in the IMR, Shenyang, China. The chemical compositions (wt.\%) of these two alloys are listed in Table 1. Prior to the study, the Ti-6Al-4V and Ti-4Al-2V-1Mo-1Fe alloys were heated to $750^{\circ} \mathrm{C}$ for $3 \mathrm{~h}$ and then cooled to room temperature in air. Samples for the immersion test were cut into sheets with dimensions of $40 \mathrm{~mm} \times 20 \mathrm{~mm} \times 4 \mathrm{~mm}$. Samples for the electrochemical test and microstructure observation were cut into square sheets $(10 \mathrm{~mm} \times 10 \mathrm{~mm} \times 2 \mathrm{~mm})$ and sealed in a mixture of epoxy and polyamide resins with an exposed surface of $1 \mathrm{~cm}^{2}$. Then each specimen was gradually ground with $\mathrm{SiC}$ papers up to 1000 grit, polished with a diamond paste of $0.5 \mu \mathrm{m}$, then cleaned in ethanol, and finally dried with hot air.

Table 1. Chemical compositions of the tested alloys (wt.\%).

\begin{tabular}{cccccc}
\hline Alloy & Al & V & Mo & Fe & Ti \\
\hline Ti-6Al-4V & 5.95 & 4.03 & - & 0.33 & Bal. \\
Ti-4Al-2V-1Mo-1Fe & 3.96 & 2.03 & 1.05 & 0.92 & Bal \\
\hline
\end{tabular}

The immersion and electrochemical tests were performed in a $3.5 \mathrm{wt} . \% \mathrm{NaCl}$ solution at 25 $\pm 1{ }^{\circ} \mathrm{C}$ (controlled by a thermostat water bath). The $3.5 \mathrm{wt} . \% \mathrm{NaCl}$ solution was prepared using analytical-grade sodium chloride and distilled water. Immersion tests were carried out to investigate the long-term corrosion behaviors of the Ti-6Al-4V and Ti-4Al-2V-1Mo-1Fe alloys. Five samples were prepared for each test solution, with an immersion period of 180 days to ensure the reproducibility. Samples with dimensions of $10 \mathrm{~mm} \times 10 \mathrm{~mm} \times 2 \mathrm{~mm}$ were successively ground with abrasive papers to 1000 grit and then were immersed in aerated $3.5 \% \mathrm{NaCl}$ solution (volume: $1.5 \mathrm{~L}$ ) without stirring. The solutions were replaced every 10 days. The electrochemical behaviors of the tested alloys were measured using a CS350 (Wuhan Corrtest Instruments Corp., Ltd. Wuhan, China) electrochemical workstation and a three-electrode electrochemical cell, and the method was described in the literature [25]. Potentiodynamic polarization was performed at a scan rate of $0.1667 \mathrm{mV} / \mathrm{s}$ from 
$-500 \mathrm{mV}_{\mathrm{SCE}}$ below the open circuit potential (OCP) and terminated at $2500 \mathrm{mV}_{\mathrm{SCE}}$. After immersing in $3.5 \mathrm{wt} . \% \mathrm{NaCl}$ solution at the OCP for $1 \mathrm{~h}$, electrochemical impedance spectroscopy (EIS) was conducted with a sinusoidal potential perturbation of $10 \mathrm{mV}$ and a frequency range from $10^{5}$ to $10^{-2} \mathrm{~Hz}$. All measurements were repeated at least three times in naturally-aerated $3.5 \mathrm{wt} . \% \mathrm{NaCl}$ solution without stirring to ensure the reproducibility. Cview and Zview software were used to fit the electrochemical data. Tensile tests of these two alloys were carried out on an Instron-type testing machine with a stain rate of $3 \mathrm{~mm} \cdot \mathrm{s}^{-1}$ at $25 \pm 1{ }^{\circ} \mathrm{C}$ [26]. To ensure the reliability of the measured data, at least three repeated measurements were carried out for each time. The standard deviation method was used to analyze the data and obtain the mechanical property parameters.

The crystal structures of the tested alloys were determined using a D/Max $2400 \mathrm{X}$-ray diffractometer (Rigaku Corporation, Tokyo, Japan) with $\mathrm{Cu} \mathrm{K}_{\alpha}$ radiation at $10 \mathrm{kV}$ and $35 \mathrm{~mA}$ at a step size of $0.02^{\circ}$ and a scan rate of $4 \% \mathrm{~min}$. The specimens used for the microstructure observation were etched in Kroll reagent ( $3 \mathrm{~mL} \mathrm{HF}, 9 \mathrm{~mL} \mathrm{HNO}_{3}$ and $88 \mathrm{~mL} \mathrm{H}_{2} \mathrm{O}$ ) for $10 \mathrm{~s}$. The microstructure was observed by a Keyence VHX-700 (Keyence Co. Ltd., Osaka, Japan) (LM) and a scanning electron microscope (XL30-FEG ESEM, FEI, Hillsboro, OR., USA) equipped with EDS. Image-Pro Plus software was used to calculate the phase volume fraction of the tested alloys.

\section{Results and Discussion}

\subsection{Microstructure Characterization}

The XRD patterns of the Ti-6Al-4V and Ti-4Al-2V-1Mo-1Fe alloys are shown in Figure 1. The diffraction peaks in Figure 1 corresponded to the peaks of $\alpha$ and $\beta$ phases, suggesting that both alloys have duplex structure. However, the proportions of these two phases in the Ti-6Al-4V and Ti-4Al-2V-1Mo-1Fe alloys were different. As seen in Figure 1, the peak intensity of $\alpha$ phase was higher, indicating a higher content of $\alpha$ phase in both alloys.
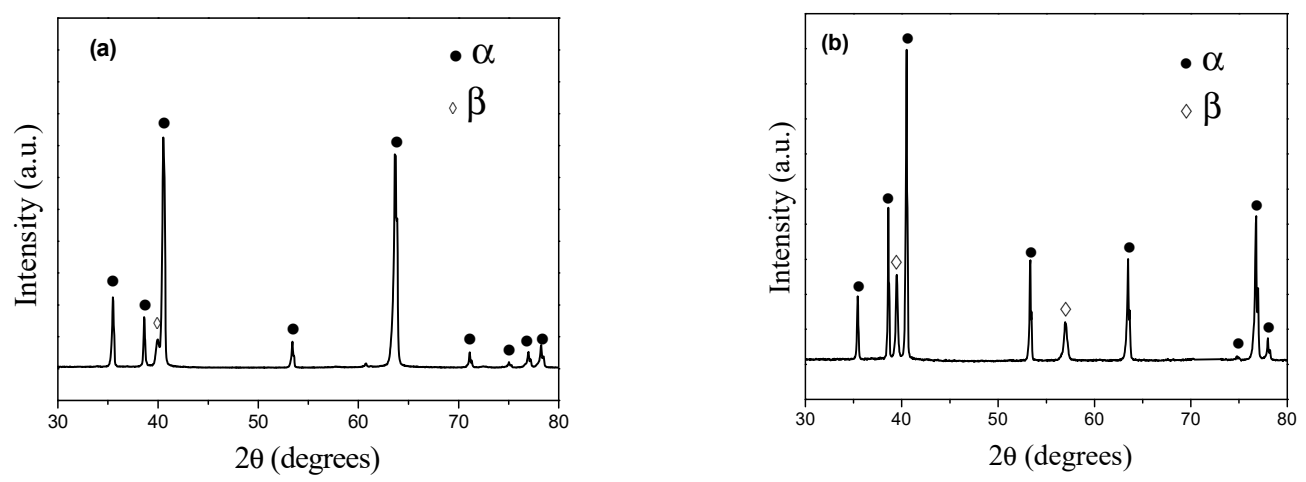

Figure 1. XRD patterns of the (a) Ti-6Al-4V and (b) Ti-4Al-2V-1Mo-1Fe alloys.

The LM images of the Ti-6Al-4V and Ti-4Al-2V-1Mo-1Fe alloys are shown in Figure 2. It was found that the two tested alloys had a bi-phase structure, consistent with the XRD results in Figure 1. The average grain size of the $\alpha$ phase in the Ti- $6 \mathrm{Al}-4 \mathrm{~V}$ alloy was $\sim 25 \mu \mathrm{m}$, and some grains were larger than $50 \mu \mathrm{m}$, as shown in Figure 2a. In comparison, the grain size of the $\alpha$ phase in the Ti-4Al-2V-1Mo-1Fe alloy was smaller, with an average grain size of about $\sim 8 \mu \mathrm{m}$, as shown in Figure $2 \mathrm{~b}$.

The SEM observations of the Ti-6Al-4V and Ti-4Al-2V-1Mo-1Fe alloys are shown in Figure 3. As seen in Figure 3, both alloys were composed of the dark $\alpha$ phase and the bright $\beta$ phase. No other precipitates were observed either inside grains or at grain boundaries. As shown in Figure 3a, the $\beta$ phase dispersed and scattered inside the equiaxed $\alpha$ phase. However, the distribution of the $\beta$ phase in the Ti-4Al-2V-1Mo-1Fe alloy was more continuous. As shown in Figure 3b, clustered $\beta$ phase distributed evenly inside the $\alpha$ phase in the Ti-4Al-2V-1Mo-1Fe alloy. The volume fraction of the $\beta$ phase in the Ti-6Al-4V and Ti-4Al-2V-1Mo-1Fe alloys was about $7.4 \%$ and $47.3 \%$, respectively. EDS 
analysis was conducted to investigate the composition of $\alpha$ and $\beta$ phases of the tested alloys, and the results are shown in Table 2 . It is reported that Fe, Mo, and V atoms have long been recognized as strong $\beta$-stabilizing elements $[19,22,27]$, thus the atomic ratio of these elements in $\beta$ phase is higher than that in $\alpha$ phase. This is mainly due to the higher element solid solubility and elemental diffusion rate in the $\beta$ phase [27,28]. Based on the research [28], the volume fraction of the $\beta$ phase in Ti-4Al-2V-1Mo- $1 \mathrm{Fe}$ alloy may be higher than that of the Ti-6Al-4V alloy.

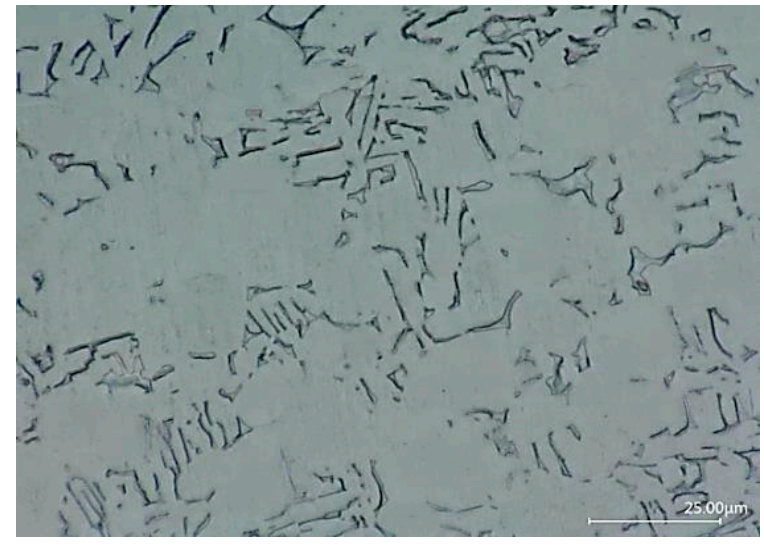

(a)

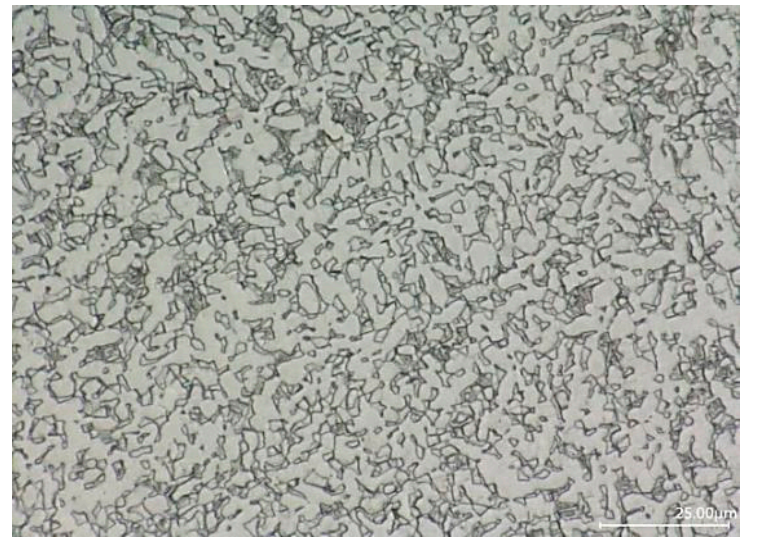

(b)

Figure 2. LM of the (a) Ti-6Al-4V and (b) Ti-4Al-2V-1Mo-1Fe alloys.
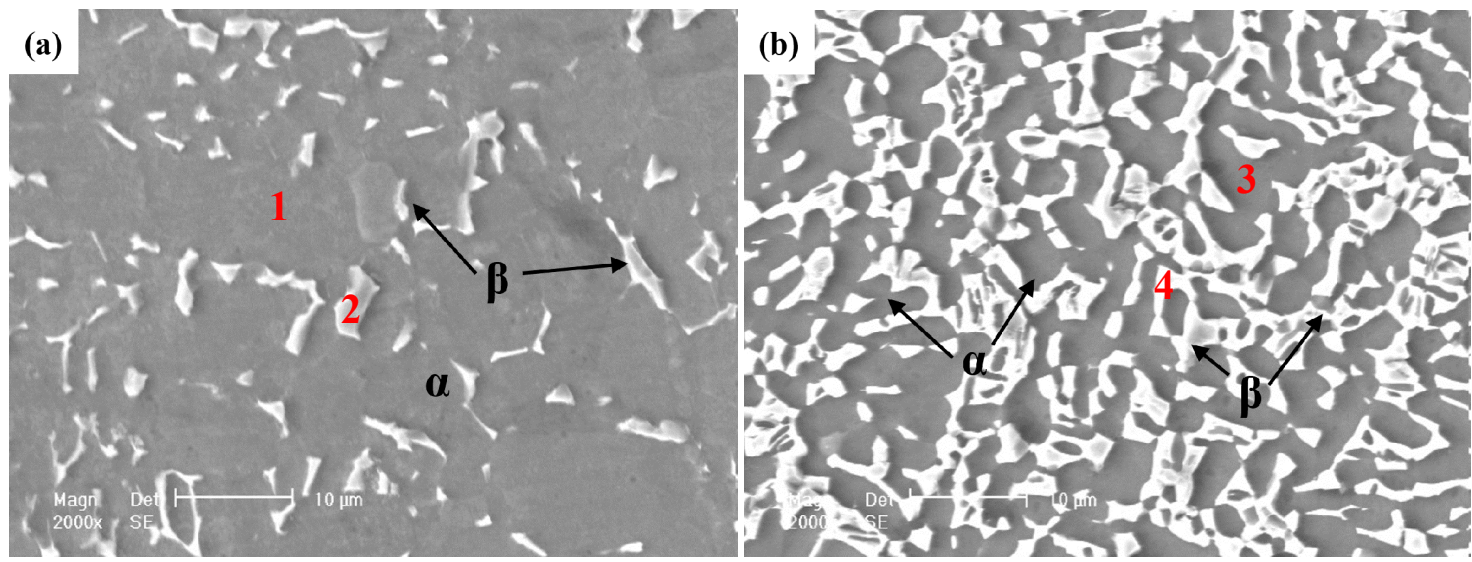

Figure 3. SEM microstructures of the (a) Ti-6Al-4V and (b) Ti-4Al-2V-1Mo-1Fe alloys.

Table 2. Chemical compositions (EDS) of $\alpha$ and $\beta$ phases of the Ti-6Al-4V and Ti-4Al-2V-1Mo-1Fe alloys (wt.\%).

\begin{tabular}{ccccccc}
\hline Alloy & & Ti & Al & V & Mo & Fe \\
\hline \multirow{2}{*}{ Ti-6Al-4V } & $\alpha$ (area 1) & 88.6 & 6.9 & 4.5 & - & - \\
& $\beta$ (area 2) & 80.7 & 2.4 & 15.9 & - & 1.0 \\
\hline \multirow{2}{*}{ Ti-4Al-2V-1Mo-1Fe } & $\alpha$ (area 3) & 93.5 & 5.3 & 1.2 & - & - \\
& $\beta$ (area 4) & 85.4 & 2.6 & 4.7 & 4.4 & 2.9 \\
\hline
\end{tabular}

\subsection{Immersion Test}

The microstructures of the Ti-6Al-4V and Ti-4Al-2V-1Mo-1Fe alloys after immersion in 3.5 wt.\% $\mathrm{NaCl}$ solution for 180 days are shown in Figure 4. It can be seen that no traces of corrosion were observed, indicating the Ti-6Al-4V and Ti-4Al-2V-1Mo-1Fe alloys had excellent corrosion resistance in 3.5 wt. \% NaCl solution. 


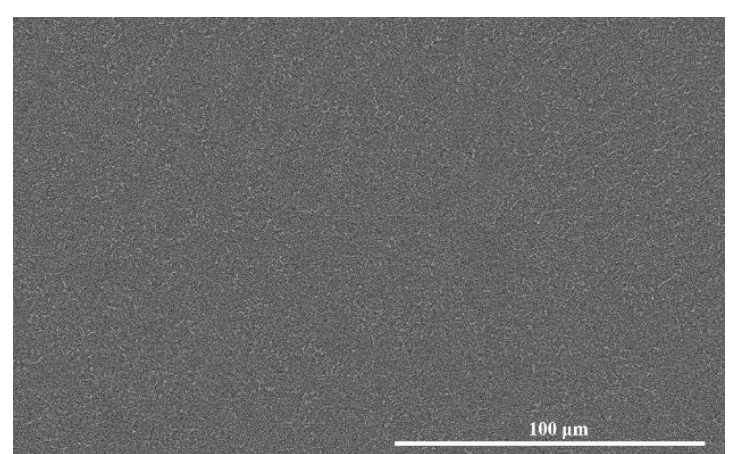

(a)

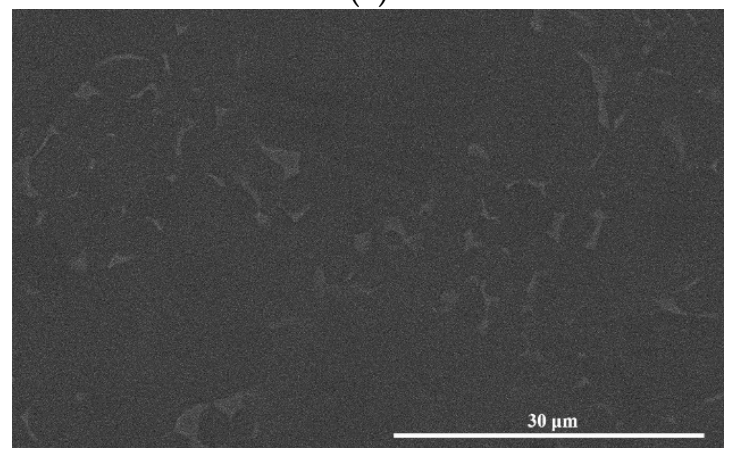

(c)

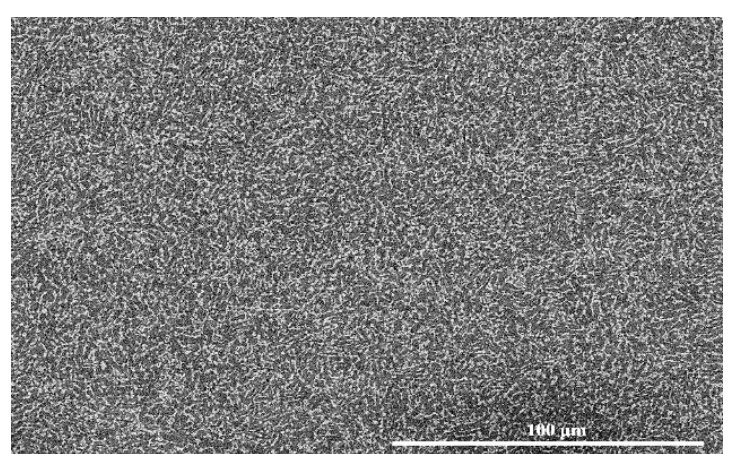

(b)

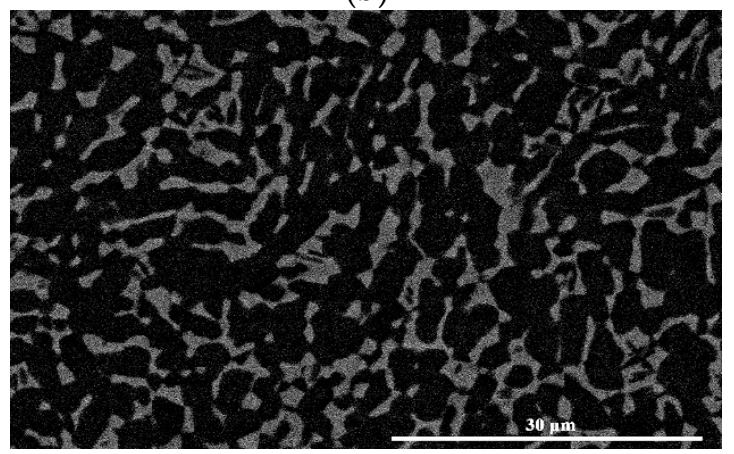

(d)

Figure 4. Microstructures of the (a,c) Ti-6Al-4V and (b,d) Ti-4Al-2V-1Mo-1Fe alloys after immersion in 3.5 wt. $\% \mathrm{NaCl}$ solution for 180 days.

The mass loss rates of the Ti-6Al-4V and Ti-4Al-2V-1Mo-1Fe alloys after 180 days of immersion in $3.5 \% \mathrm{NaCl}$ solution were calculated based on the mass loss, $\Delta m$, using Equation (1) shown as following:

$$
\Delta m=\frac{m_{0}-m_{1}}{S \times t}
$$

where $m_{0}$ is the weight $(\mathrm{mg})$ of the sample before the immersion test, $m_{1}$ is the weight $(\mathrm{mg})$ of the sample after the immersion test, $S$ is the surface area of the sample $\left(\mathrm{cm}^{2}\right)$, and $t$ is the immersion time (180 days). The mass loss rate of the Ti-6Al-4V and Ti-4Al-2V-1Mo-1Fe alloys was $1.99 \times 10^{-4}$ and $2.01 \times 10^{-4} \mathrm{mg} \cdot \mathrm{cm}^{-2} \cdot$ day $^{-1}$, respectively. This indicates both behaved similarly, without any obvious occurrence of corrosion in the present tested solution.

\subsection{Electrochemical Response}

Once the Ti-6Al-4V and Ti-4Al-2V-1Mo-1Fe alloys were immersed in $\mathrm{NaCl}$ solution at OCP, the dissolution process of the naturally-formed oxide film $\left(\right.$ rutile $\left.\mathrm{TiO}_{2}\right)$ in air began and the self-passivated film simultaneously formed [9]. The OCPs for the Ti-6Al-4V and Ti-4Al-2V-1Mo-1Fe alloys in $3.5 \mathrm{wt} . \%$ $\mathrm{NaCl}$ solution are shown in Figure 5. Since the specimens were exposed in ambient atmosphere for 1 $\mathrm{h}$ to allow the native growth of oxide film, the spontaneous OCP after the immersion indicated the stability of the naturally-formed oxide [5]. It is seen from Figure 5 that corrosion potential $\left(E_{c o r r}\right)$ of the Ti-6Al-4V alloy shifted continuously to positive potential with the immersion time. As for the Ti-4Al-2V-1Mo-1Fe alloy, the $E_{\text {corr }}$ gradually increased from $-0.65 \mathrm{~V}_{\mathrm{SCE}}$ to more noble potential, and finally achieved steady-state potential of $-0.40 \mathrm{~V}_{\mathrm{SCE}}$ when the immersion time was $1 \mathrm{~h}$. The corrosion data in Figure 5 revealed that a shorter time was required for the steady-state potentials to be obtained in $3.5 \mathrm{wt}$ \% $\mathrm{NaCl}$ solution for the Ti-4Al-2V-1Mo-1Fe alloy compared to the Ti-6Al-4V alloy. 


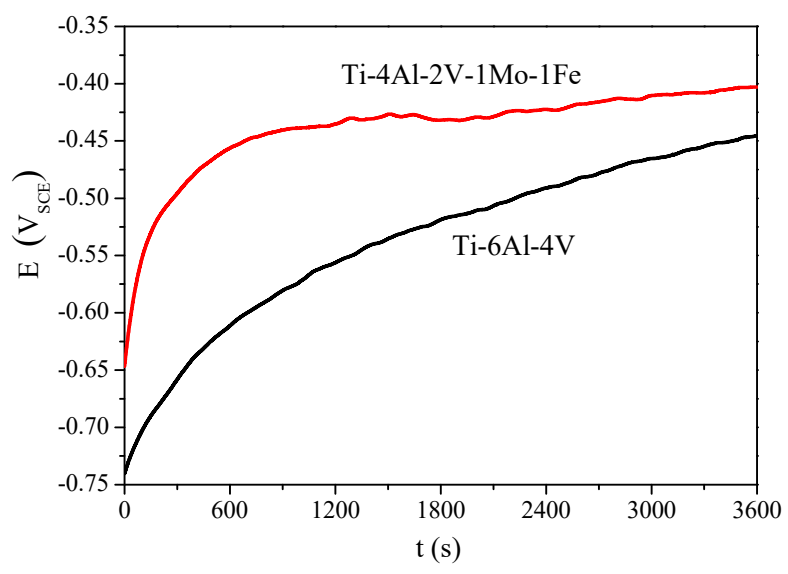

Figure 5. Evolution of open circuit potential (OCP) with immersion time for the Ti-6Al-4V and Ti-4Al-2V-1Mo-1Fe alloys in $3.5 \mathrm{wt} . \% \mathrm{NaCl}$ solution.

To investigate the stability of the passive film formed on the Ti-6Al-4V and Ti-4Al-2V-1Mo-1Fe alloys, EIS measurements were carried out at OCP for both alloys in $3.5 \mathrm{wt} . \% \mathrm{NaCl}$ solution. Figures 6 and 7 show the Nyquist and Bode plots for the Ti-6Al-4V and Ti-4Al-2V-1Mo-1Fe alloys for $1 \mathrm{~h}$ immersion in $3.5 \mathrm{wt} . \% \mathrm{NaCl}$ solution. As seen from Figure 6, both the Ti-6Al-4V and Ti-4Al-2V-1Mo-1Fe alloys exhibited an unfinished single capacitive arc. It can be seen in Figure 7 that only one time constant was observed. The initial impedance $(Z)$ recorded for the Ti-4Al-2V-1Mo-1Fe alloy was higher than that of the Ti-6Al-4V alloy, indicating that the Ti-4Al-2V-1Mo-1Fe alloy had a superior corrosion resistance [3]. The impedance data were analyzed using the equivalent circuit shown in Figure 8. The use of a constant phase element (CPE) was necessary [29-31] due to the distribution of relaxation times resulting from heterogeneities at the electrode surface. The CPE was used for the description of a frequency-independent phase shift between an applied AC potential and its current response [32], and has been extensively investigated $[29,33]$. The impedance of the CPE was given by:

$$
Z_{C P E}=\frac{1}{Q}(j \omega)^{-n}
$$

Therefore, the total impedance was [34]:

$$
Z_{\text {total }}=R_{s}+\left(Q(j \omega)^{n}+\frac{1}{R_{p}}\right)^{-1}
$$

where $n$ was the depression angle (in degrees) that evaluated the semicircle deformation, $R_{s}$ was the electrolyte resistance, $R_{p}$ represented the charge transfer resistance, and $Q$ corresponded to the pseudo-capacitance of the film, expressed using the CPE. The reason may be as follows: the CPE accounted for two contributions, one arising from double-layer capacitance $\left(C_{H}\right)$ and one arising from semiconductor capacitance relating to the passive film (Csc). The capacitance of the double layer seems to be neglected according to the result reported by Hirschorn et al. [35], so the capacitance behavior of Ti-6Al-4V and Ti-4Al-2V-1Mo-1Fe alloys was dominated by the passive film [36]. Table 3 shows the values of the electric parameters obtained using the equivalent electric circuit to fit the EIS data. It is seen in Table 3 that the film resistance for the Ti-6Al-4V and Ti-4Al-2V-1Mo-1Fe alloys was $5.69 \times 10^{5}$ $\Omega \cdot \mathrm{cm}^{-2}$ and $6.50 \times 10^{5} \Omega \cdot \mathrm{cm}^{-2}$, respectively. It is consistent with the generally accepted sense that a larger capacitive arc indicates higher corrosion resistance. It can be inferred that the stability of the passive film formed on the Ti-4Al-2V-1Mo-1Fe alloy in the present solution was slightly better than that of the Ti-6Al-4V alloy. 


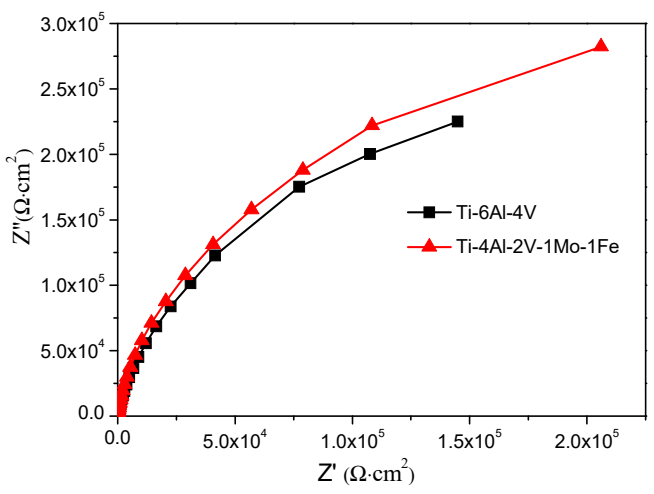

Figure 6. Nyquist plots for the Ti-6Al-4V and Ti-4Al-2V-1Mo-1Fe alloys for $1 \mathrm{~h}$ of immersion in 3.5 wt.\% $\mathrm{NaCl}$ solution.

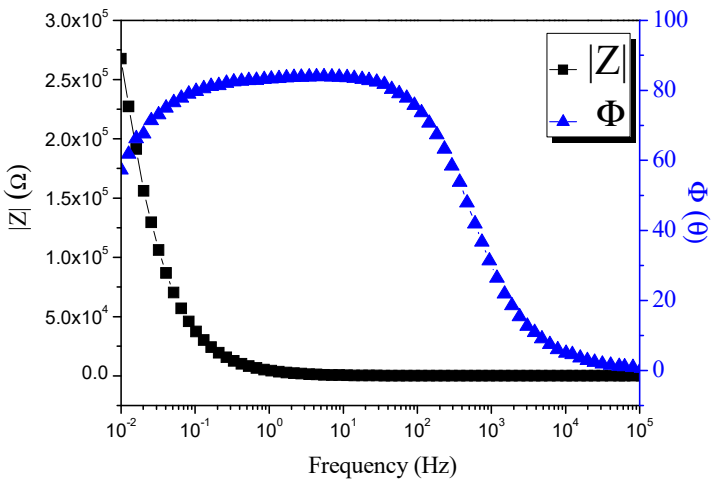

(a)

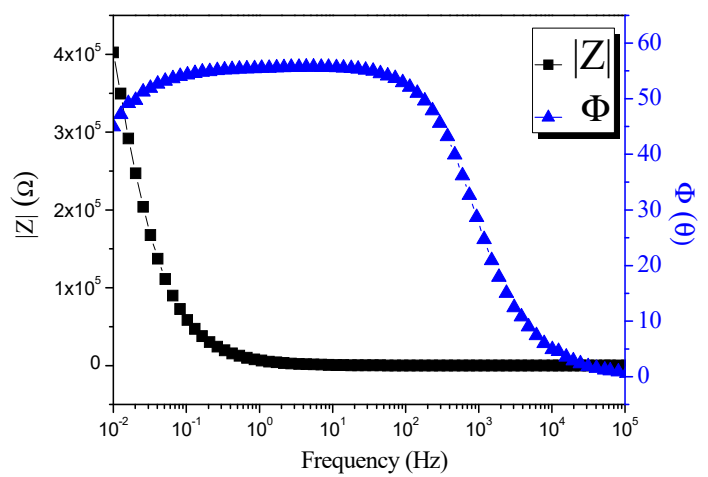

(b)

Figure 7. Bode plots for the (a) Ti-6Al-4V and (b) Ti-4Al-2V-1Mo-1Fe alloys for $1 \mathrm{~h}$ of immersion in 3.5 wt. $\% \mathrm{NaCl}$ solution.

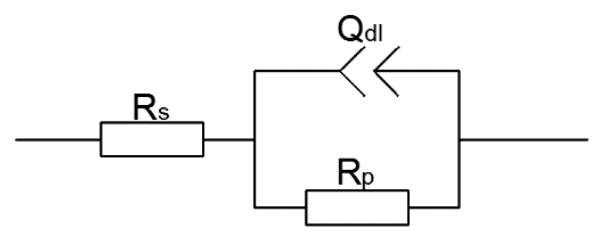

Figure 8. The equivalent circuit used for quantitative evaluation of electrochemical impedance spectroscopy (EIS).

Table 3. The EIS fitted data of Ti-6Al-4V and Ti-4Al-2V-1Mo-1Fe alloys.

\begin{tabular}{ccccc}
\hline Alloy & $\boldsymbol{R}_{\boldsymbol{s}}\left(\boldsymbol{\Omega} \cdot \mathbf{c m}^{-\mathbf{2}}\right)$ & $\boldsymbol{R}_{\boldsymbol{p}}\left(\boldsymbol{\Omega} \cdot \mathbf{c m}^{-\mathbf{2}}\right)$ & $\boldsymbol{Q}\left(\boldsymbol{\Omega}^{-\mathbf{1}} \cdot \mathbf{S}^{\mathbf{n}} \cdot \mathbf{c m}^{-\mathbf{2}}\right)$ & $n$ \\
\hline Ti-6Al-4V & $10.89 \pm 1.12$ & $5.69 \pm 0.13 \times 10^{5}$ & $3.98 \pm 0.32 \times 10^{-5}$ & $0.93 \pm 0.01$ \\
Ti-4Al-2V-1Mo-1Fe & $8.71 \pm 0.87$ & $6.50 \pm 0.35 \times 10^{5}$ & $2.56 \pm 0.26 \times 10^{-5}$ & $0.95 \pm 0.01$ \\
\hline
\end{tabular}

The potentiodynamic polarization curves for the Ti-6Al-4V and Ti-4Al-2V-1Mo-1Fe alloys in 3.5 wt.\% $\mathrm{NaCl}$ solution are shown in Figure 9. It is seen from Figure 9 that the corrosion behaviors of the Ti-6Al-4V and Ti-4Al-2V-1Mo-1Fe alloys were similar. Both alloys were typically passive materials, displaying a wide passive region from $0.11 \pm 0.03 \mathrm{~V}_{\mathrm{SCE}}$ to $2.5 \pm 0.05 \mathrm{~V}_{\mathrm{SCE}}$. After the potential was scanned to $2.5 \mathrm{~V}_{\mathrm{SCE}}$ in $3.5 \mathrm{wt}$ \% $\mathrm{NaCl}$ solution, no film breakdown was observed. This clearly indicates the passive film forming spontaneously on the Ti-6Al-4V and Ti-4Al-2V-1Mo-1Fe alloys surfaces was thermodynamically stable [37]. It is reported that $\mathrm{Al}$ or Fe could be oxidized and form a compact $\mathrm{Al}$ 
and Fe oxide layer on the top of passive film, inhibiting the dissolution of the oxide film [22]. The corrosion current density $\left(i_{\text {corr }}\right)$ for the Ti-6Al-4V and Ti-4Al-2V-1Mo-1Fe alloys was $2.23 \pm 0.41 \times 10^{-7}$ $\mathrm{A} \cdot \mathrm{cm}^{-2}$ and $1.51 \pm 0.22 \times 10^{-7} \mathrm{~A} \cdot \mathrm{cm}^{-2}$, respectively. Compared to the Ti-4Al-2V-1Mo-1Fe alloy, the lower $E_{\text {corr }}$ and higher $i_{\text {corr }}$ of the Ti-6Al-4V alloy suggested that the Ti-4Al-2V-1Mo-1Fe alloy had a higher corrosion resistance, consistent with the results of EIS test.

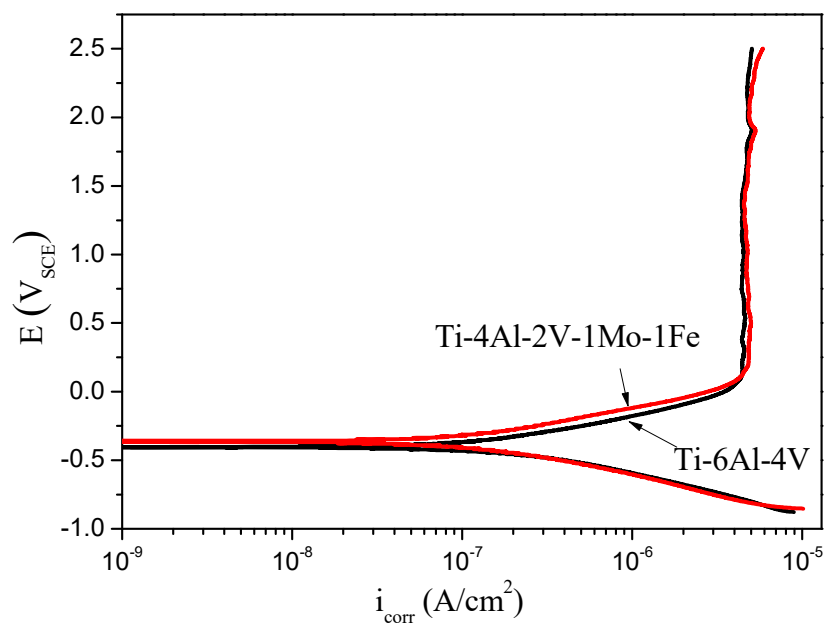

Figure 9. Potentiodynamic polarization curves of Ti-6Al-4V and Ti-4Al-2V-1Mo-1Fe alloys in 3.5 wt.\% $\mathrm{NaCl}$ solution.

The corrosion resistance of titanium alloy relies on the stability of its passive film. The formation of passive layer requires the transfer of titanium and hydroxyl ions as follows [38]:

$$
\mathrm{Ti} \rightarrow \mathrm{Ti}^{2+}+2 \mathrm{e}^{-}
$$

Since $\mathrm{Ti}^{2+}$ is unstable, it will react with $\mathrm{H}_{2} \mathrm{O}$ and produce $\mathrm{Ti}^{3+}$ once it is formed;

$$
\begin{gathered}
2 \mathrm{Ti}^{2+}+2 \mathrm{H}_{2} \mathrm{O} \rightarrow 2 \mathrm{Ti}^{3+}+2 \mathrm{OH}^{-}+\mathrm{H}_{2} \\
\mathrm{Ti}^{2+}+3 \mathrm{OH}^{-} \rightarrow \mathrm{Ti}(\mathrm{OH})_{3}
\end{gathered}
$$

Transformation of $\mathrm{Ti}(\mathrm{OH})_{3}$ might take place to hydrated $\mathrm{TiO}_{2}$ layer in a dynamic equilibrium reaction as follows:

$$
2 \mathrm{Ti}(\mathrm{OH})_{3} \rightarrow \mathrm{TiO}_{2} \cdot \mathrm{H}_{2} \mathrm{O}+\mathrm{H}_{2}
$$

In addition, the corrosion resistance of the Ti-4Al-2V-1Mo-1Fe alloy was slightly higher than the Ti-6Al-4V alloy, which was mainly due to the fact that the Ti-4Al-2V-1Mo-1Fe alloy contained Mo elements, making the passive film more stable [39].

\subsection{Mechanical Properties}

Figure 10 shows typical tensile curves of the Ti-6Al-4V and Ti-4Al-2V-1Mo-1Fe alloys. The specific mechanical property values including the tensile $R_{m}$, yield stress $R_{p 0.2}$ strength, and elongation $\varepsilon$ from the tensile curves, are summarized in Table 4 . It shows that strength of the Ti-4Al-2V-1Mo-1Fe alloy was slightly lower but its elongation was higher compared to the Ti-6Al-4V alloy (yield strength of 838 MPa vs. $968 \mathrm{MPa}$, and the elongation of $15.8 \%$ vs. $13.8 \%$ ). Since the volume fractions of the $\alpha$ and $\beta$ phases were different in Ti-6Al-4V and Ti-4Al-2V-1Mo-1Fe alloys, these will have influences on their tensile properties. Moreover, the $\alpha$ phase had more slip systems and the $\beta$ phases had limited slip systems according to their structure identified by XRD in Figure 1. Therefore, the stress concentration 
at $\alpha / \beta$ phase interfaces could be easily induced in the tensile tests due to the incompatible plastic deformation between two phases. Then, micro-cracks would preferentially initiate at the $\alpha / \beta$ phase interfaces. The fracture morphologies of the tensile test for the Ti-6Al-4V and Ti-4Al-2V-1Mo-1Fe alloys are displayed in Figure 11. Many dimples were observed in Figure 11, and the Ti-6Al-4V and Ti-4Al-2V-1Mo-1Fe alloys were typically transgranular with a dimple fracture [40].

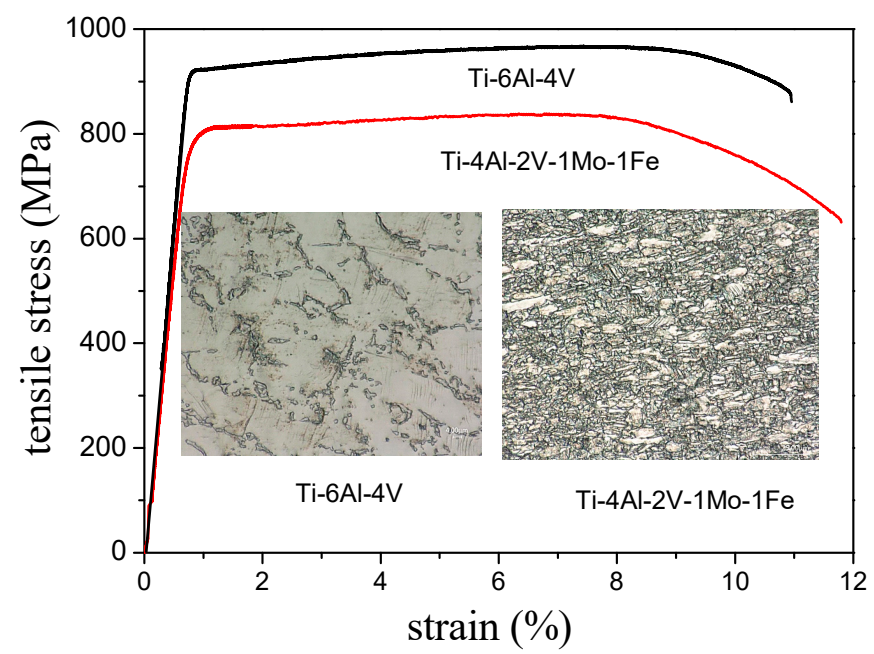

Figure 10. Tensile stress-strain curves of the Ti-6Al-4V and Ti-4Al-2V-1Mo-1Fe alloys.

Table 4. Mechanical parameters of the Ti-6Al-4V and Ti-4Al-2V-1Mo-1Fe alloys.

\begin{tabular}{cccc}
\hline Alloy & $\boldsymbol{R}_{\boldsymbol{m}} \mathbf{( M P a )}$ & $\boldsymbol{R}_{\boldsymbol{p 0 . 2}} \mathbf{( M P a )}$ & $\boldsymbol{\varepsilon} \mathbf{( \% )}$ \\
\hline Ti-6Al-4V & $968 \pm 22.1$ & $921 \pm 15.4$ & $13.8 \pm 1.1$ \\
Ti-4Al-2V-1Mo-1Fe & $838 \pm 16.3$ & $796 \pm 14.3$ & $15.8 \pm 1.3$ \\
\hline
\end{tabular}
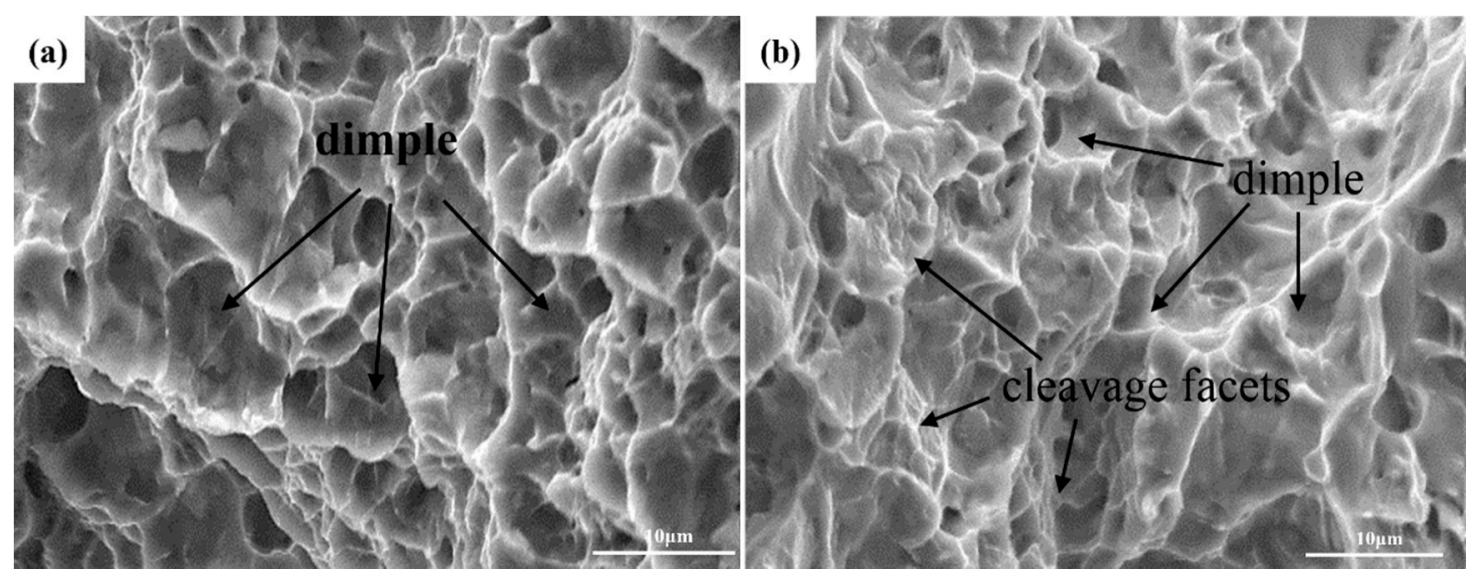

Figure 11. Fractography of the (a) Ti-6Al-4V and (b) Ti-4Al-2V-1Mo-1Fe alloys.

\section{Conclusions}

In this paper, the corrosion and tensile behaviors of the Ti-6Al-4V and Ti-4Al-2V-1Mo-1Fe alloys were investigated. The results were summarized as follows.

(1) Both Ti-6Al-4V and Ti-4Al-2V-1Mo-1Fe alloys were composed of the $\alpha$ and $\beta$ phases. The volume fractions of the $\beta$ phase in these two alloys were $7.4 \%$ and $47.3 \%$.

(2) Both Ti-6Al-4V and Ti-4Al-2V-1Mo-1Fe alloys presented excellent corrosion resistance in 3.5 wt.\% NaCl solution. No obvious corrosion was observed on the surface of the two alloys after immersion in 3.5 wt.\% NaCl for 180 days. Compared to the Ti-6Al-4V alloy, the higher Mo content 
in the Ti-4Al-2V-1Mo-1Fe alloy increased the stability of passivation film, and showed an increased corrosion resistance.

(3) Compared to the Ti-6Al-4V alloy, the Ti-4Al-2V-1Mo-1Fe alloy presented a slightly lower strength and higher ductility.

Author Contributions: Data curation, Y.W. and H.Z.; funding acquisition, Y.M.; methodology, D.X. and Y.M.; writing—original draft, Y.Q. and S.W.; writing—review and editing, J.C.

Funding: This research received no external funding.

Acknowledgments: The authors acknowledge the financial support of the National Natural Science Foundation of China (No. 51871225), National Key Research and Development Program of China [2018YFC0310400], and Natural Science Foundation of the Higher Education Institutions of Jiangsu Province, China [18KJB460007].

Conflicts of Interest: The authors declare no conflict of interest.

\section{References}

1. Boyer, R.R. An overview on the use of titanium in the aerospace industry. Mater. Sci. Eng. A 1996, 213, 103-144. [CrossRef]

2. Zhang, H.; Li, J.L.; Ma, P.Y.; Xiong, J.T.; Zhang, F.S. Study on microstructure and impact toughness of TC4 titanium alloy diffusion bonding joint. Vacuum 2018, 152, 272-277. [CrossRef]

3. Nady, H.; El-Rabiei, M.M.; Samy, M. Corrosion behavior and electrochemical properties of carbon steel, commercial pure titanium, copper and copper-aluminum-nickel alloy in 3.5\% sodium chloride containing sulfide ions. Egypt. J. Pet. 2017, 26, 79-94. [CrossRef]

4. Cui, Z.Y.; Wang, L.W.; Zhong, M.Y.; Ge, F.; Gao, H.; Man, C.; Liu, C.; Wang, X. Electrochemical behavior and surface characteristics of pure titanium during corrosion in simulated desulfurized flue gas Condensates. $J$. Electrochem. Soc. 2018, 165, C542. [CrossRef]

5. Wang, Z.B.; Hu, H.X.; Zheng, Y.G.; Ke, W.; Qiao, Y.X. Comparison of the corrosion behavior of pure titanium and its alloys in fluoride-containing sulfuric acid. Corros. Sci. 2016, 103, 50-65. [CrossRef]

6. Contu, F.; Elsener, B.; Böhni, H. Serum effect on the electrochemical behaviour of titanium, Ti6Al4V and Ti6Al7Nb alloys in sulphuric acid and sodium hydroxide. Corros. Sci. 2004, 46, 2241-2254. [CrossRef]

7. Narayanan, R.; Seshadri, S.K. Point defect model and corrosion of anodic oxide coatings on Ti-6Al-4V. Corros. Sci. 2008, 50, 1521-1529. [CrossRef]

8. Tamilselvi, S.; Raman, V.; Rajendran, N. Evaluation of corrosion behavior of surface modified Ti-6Al-4V ELI alloy in hanks solution. J. Appl. Electrochem. 2010, 40, 285-293. [CrossRef]

9. Rai, S.; Dihingia, P.J. Optoelectronics of $\mathrm{Cu}^{2+}$-Doped TiO $\mathrm{O}_{2}$ Films Prepared by Sol.-Gel Method; Springer India: New Delhi, India, 2015; pp. 581-589.

10. Hugot-Le Goff, A. Structure of very thin $\mathrm{TiO}_{2}$ films studied by Raman spectroscopy with interference enhancement. Thin Solid Films 1986, 142, 193-197. [CrossRef]

11. Diamanti, M.V.; Souier, T.; Stefancich, M.; Chiesa, M.; Pedeferri, M.P. Probing anodic oxidation kinetics and nanoscale heterogeneity within $\mathrm{TiO}_{2}$ films by conductive Atomic Force Microscopy and combined techniques. Electrochim. Acta 2014, 129, 203-210. [CrossRef]

12. Yue, T.M.; Yu, J.K.; Mei, Z.; Man, H.C. Excimer laser surface treatment of Ti-6Al-4V alloy for corrosion resistance enhancement. Mater. Lett. 2002, 52, 206-212. [CrossRef]

13. Blanco-Pinzon, C.; Liu, Z.; Voisey, K.; Bonilla, F.A.; Skeldon, P.; Thompson, G.E.; Piekoszewski, J.; Chmielewski, A.G. Excimer laser surface alloying of titanium with nickel and palladium for increased corrosion resistance. Corros. Sci. 2005, 47, 1251-1269. [CrossRef]

14. Newman, R.C. The dissolution and passivation kinetics of stainless alloys containing molybdenum- I. Coulometric studies of Fe-Cr and Fe-Cr-Mo alloys. Corros. Sci. 1985, 25, 331-339. [CrossRef]

15. Newman, R.C. The dissolution and passivation kinetics of stainless alloys containing molybdenum-II. Dissolution kinetics in artificial pits. Corros. Sci. 1985, 25, 341-350. [CrossRef]

16. Marcus, P. On some fundamental factors in the effect of alloying elements on passivation of alloys. Corros. Sci. 1994, 36, 2155-2458. [CrossRef]

17. Ouchi, C.; Fukai, H.; Hasegawa, K. Microstructural characteristics and unique properties obtained by solution treating or aging in $\beta$-rich $\alpha+\beta$ titanium alloy. Mater. Sci. Eng. A 1999, 263, 132-136. [CrossRef] 
18. Erween Abd, R.; Safian, S. Investigation on tool life and surface integrity when drilling Ti-6Al-4V and Ti-5Al-4V-Mo/Fe. JSME Int. J. Ser. C 2006, 49, 340-345.

19. Lin, D.J.; Lin, J.H.C.; Ju, C.P. Structure and properties of Ti-7.5Mo-xFe alloys. Biomaterials 2002, 23, $1723-1730$. [CrossRef]

20. Prodana, M.; Bojin, D.; Ioniţǎ, D. Effect of hydroxyapatite on interface properties for alloy/biofluid. UPB Sci. Bull. Ser. B Chem. Mater. Sci. 2009, 71, 89-98.

21. Pimenova, N.V.; Starr, T.L. Electrochemical and corrosion behavior of Ti-xAl-yFe alloys prepared by direct metal deposition method. Electrochim. Acta 2006, 51, 2042-2049. [CrossRef]

22. Lu, J.W.; Zhao, Y.Q.; Niu, H.Z.; Zhang, Y.S.; Du, Y.Z.; Zhang, W.; Huo, W.T. Electrochemical corrosion behavior and elasticity properties of Ti-6Al-xFe alloys for biomedical applications. Mater. Sci. Eng. C 2016, 62, 36-44. [CrossRef] [PubMed]

23. Hsu, H.C.; Pan, C.H.; Wu, S.C.; Ho, W.F. Structure and grindability of cast Ti-5Cr-xFe alloys. J. Alloy. Compd. 2009, 474, 578-583. [CrossRef]

24. Hsu, H.C.; Hsu, S.K.; Wu, S.C.; Lee, C.J.; Ho, W.F. Structure and mechanical properties of as-cast Ti-5Nb-xFe alloys. Mater. Charact. 2010, 61, 851-858. [CrossRef]

25. Qiao, Y.X.; Cai, X.; Cui, J.; Li, H.B. Passivity and semiconducting behavior of a high nitrogen stainless steel in acidic $\mathrm{NaCl}$ solution. Adv. Mater. Sci. Eng. 2016, 6065481, 1-8. [CrossRef]

26. Qiao, Y.X.; Chen, J.; Zhou, H.L.; Wang, Y.X.; Song, Q.N.; Li, H.B.; Zheng, Z.B. Effect of solution treatment on cavitation erosion behavior of high-nitrogen austenitic stainless steel. Wear 2019, 424-425, 70-77. [CrossRef]

27. Huang, S.S.; Ma, Y.J.; Ping, Z.Y.; Zhang, S.L.; Yang, R. Influence of alloying elements partitioning behaviors on the microstructure and mechanical properties in $\alpha+\beta$ titanium alloy. Acta Metall. Sin. 2019, 55, 741-750.

28. Huang, S.S.; Zhang, J.H.; Ma, Y.J.; Zhang, S.L.; Youssef, S.S.; Qi, M.; Wang, H.; Qiu, J.K.; Xu, D.S.; Lei, J.F.; et al. Influence of thermal treatment on element partitioning in $\alpha+\beta$ titanium alloy. J. Alloy. Compd. 2019, 791, 575-585. [CrossRef]

29. Qiao, Y.X.; Tian, Z.H.; Cai, X.; Chen, J.; Wang, Y.X.; Song, Q.N.; Li, H.B. Cavitation erosion behaviors of a nickel-free high-nitrogen stainless steel. Tribol. Lett. 2019, 67, 1-9. [CrossRef]

30. Carnot, A.; Frateur, I.; Zanna, S.; Tribollet, B.; Dubois-Brugger, I.; Marcus, P. Corrosion mechanisms of steel concrete moulds in contact with a demoulding agent studied by EIS and XPS. Corros. Sci. 2003, 45, 2513-2524. [CrossRef]

31. Hitz, C.; Lasia, A. Experimental study and modeling of impedance of the her on porous Ni electrodes. J. Electroanal. Chem. 2001, 500, 213-222. [CrossRef]

32. Jeyaprabha, C.; Sathiyanarayanan, S.; Venkatachari, G. Influence of halide ions on the adsorption of diphenylamine on iron in $0.5 \mathrm{M} \mathrm{H}_{2} \mathrm{SO}_{4}$ solutions. Electrochim. Acta 2006, 51, 4080-4088. [CrossRef]

33. Qiao, Y.X.; Zheng, Y.G.; Ke, W.; Okafor, P.C. Electrochemical behaviour of high nitrogen stainless steel in acidic solutions. Corros. Sci. 2009, 51, 979-986. [CrossRef]

34. Grubač, Z.; Metikoš-Huković, M. EIS study of solid-state transformations in the passivation process of bismuth in sulfide solution. J. Electroanal. Chem. 2004, 565, 85-94. [CrossRef]

35. Hirschorn, B.; Orazem, M.E.; Tribollet, B.; Vivier, V.; Frateur, I.; Musiani, M. Determination of effective capacitance and film thickness from constant-phase-element parameters. Electrochim. Acta 2010, 55, 6218-6227. [CrossRef]

36. Wang, Z.B.; Hu, H.X.; Liu, C.B.; Zheng, Y.G. The effect of fluoride ions on the corrosion behavior of pure titanium in 0.05M sulfuric acid. Electrochim. Acta 2014, 135, 526-535. [CrossRef]

37. Cao, C.N. Theory of Electrochemical; Chemical Industry Press: Beijing, China, 2004; pp. 24-35.

38. Ibrahim, M.A.; Pongkao, D.; Yoshimura, M. The electrochemical behavior and characterization of the anodic oxide film formed on titanium in $\mathrm{NaOH}$ solutions. J. Solid State Electrochem. 2002, 6, 341-350. [CrossRef]

39. Wang, B.J.; Xu, D.K.; Wang, S.D.; Han, E.H. Recent progress in the research about fatigue crack initiation of Mg alloys under elastic stress amplitudes: A review. Front. Mech. Eng. 2019, 14, 113-127. [CrossRef]

40. Wang, B.J.; Xu, D.K.; Wang, S.D.; Sheng, L.Y.; Zeng, R.C.; Han, E.H. Influence of solution treatment on the corrosion fatigue behavior of an as forged Mg-Zn-Y.-Zr alloy. Int. J. Fatigue 2019, 120, 46-55. [CrossRef]

(C) 2019 by the authors. Licensee MDPI, Basel, Switzerland. This article is an open access article distributed under the terms and conditions of the Creative Commons Attribution (CC BY) license (http://creativecommons.org/licenses/by/4.0/). 